\title{
Digestibilidade Aparente e Desenvolvimento de Eqüinos em Crescimento Submetidos a Dietas Compostas por Diferentes Níveis de Substituição do Feno de Tifton 85 pela Casca de Soja ${ }^{1}$
}

\author{
João Batista da Silva Quadros², Carlos Eduardo Furtado3 ${ }^{3}$ Eder Dias Barbosa ${ }^{4}$, Marilia \\ Belisário de Andrade ${ }^{4}$, Alexandre Garcia Trevisan ${ }^{5}$
}

\begin{abstract}
RESUMO - Dois experimentos foram conduzidos com o objetivo de avaliar nutricionalmente a utilização da casca de soja na alimentação de eqüinos em crescimento. Foram utilizadas quatro dietas, uma ração testemunha e três dietas teste, nas quais a casca de soja substituiu em 33,3; 66,6 e 100\% o feno de Tifton 85 . No ensaio de digestibilidade, foram utilizados quatro potros, com 11 meses de idade, peso vivo médio de $350 \pm 26 \mathrm{~kg}$, para determinar o valor nutritivo das rações contendo diferentes níveis de casca de soja, utilizando delineamento experimental em quadrado latino (4 períodos $\mathrm{x} 4$ animais). Os coeficientes de digestibilidade aparente da matéria seca, fibra bruta, fibra em detergente neutro e fibra em detergente ácido apresentaram valores de 62,48, 66,35, 79,49 e 82,77\%; 66,08, 65,16, 75,41 e 74,09\%; 62,59, 62,62, 75,17 e 74,05\% e 61,12, 57,15, 73,34 e 72,27\%, respectivamente, para as dietas testemunha e com 33,3, 66,6 e $100 \%$ de substituição do feno de Tifton 85 pela casca de soja. Os coeficientes de digestibilidade aparente da proteína bruta não apresentaram diferenças significativas (valores médios, respectivamente, de 69,67, 71,95, 74,08 e 75,03\% para as dietas testemunha e com 33,3, 66,6 e 100\% de substituição do feno de Tifton 85 pela casca de soja). No experimento de desempenho, foram utilizados 16

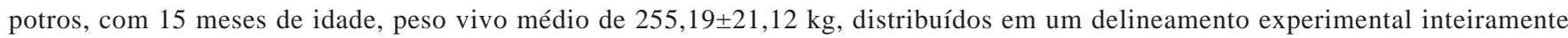
casualizado, com quatro repetições e quatro animais por unidade experimental durante 75 dias. Não foram verificados efeitos das dietas sobre as variáveis de desempenho de eqüinos em crescimento. Concluiu-se que as dietas para eqüinos podem ser formuladas com substituição total do feno de Tifton 85 pela casca de soja, sem afetar o desempenho.
\end{abstract}

Palavras-chave: casca de soja, desenvolvimento, digestibilidade, feno de gramínea, potros

\section{Apparent Digestibility and Development of Growing Horses Fed Diets With Different Levels of Substitution of Tifton 85 Hay for Soybean Hulls}

\begin{abstract}
Two experiments were carried out to evaluate the nutritional utilization of soybean hulls for growing horses. In the digestibility assay, four colts, averaging 11 months of age and $350 \pm 26 \mathrm{~kg}$, were used to determine the nutritional value of diets with soybean hulls. The experimental design was square latine $(4 \mathrm{x} 4)$. Four diets were used, one as a reference and three as test diets, where the soybean hulls replaced 33.3, 66.6 and $100 \%$ of the Tifton 85 hay of the reference diet. Total feces collection was used to determine the apparent digestibility coefficients of the diets. Effects on the apparent digestibility coefficient of the dry matter were observed (62.48, 66.35 , 79.49 and $82.77 \%$; 66.08, 65.16, 75.41 and 74.09\%; 62.59, 62.62, 75.17 and 74.05\% and 61.12, 57.15, 73.34 and 72.27\%, respectively, for the test diet and the diets with 33.3, 66.6 and 100\% of soybean hulls replacing the Tifton 85 hay). No effects on the apparent digestibility coefficients of crude protein were observed (69.67, 71.95, 74.08 and 75.03\%, respectively, for the test diet and the diets with 33.3, 66.6 and $100 \%$ of soybean hulls replacing the Tifton 85 hay. In the development experiment, 16 colts, averaging 15 months of age and $255.19 \pm 21.12 \mathrm{~kg}$, were used. A completely randomized design with four replications and four animal by each experimental unit, for a period of 75 days, was used. The trials consisted of a reference diet and three levels of substitution (33.3, 66.6 and 100\%) of hay by soybean hulls, formulated to be isoprotein and isocaloric. No diet effects on the perfomance variables were observed in growing horses. It was concluded that diets for equines can be formulated with total substitution of hay for soybean hulls without affecting development.
\end{abstract}

Key Words: digestibility coefficient, development, foals, grass hay, soybean hulls

\footnotetext{
${ }^{1}$ Parte da Dissertação de Mestrado apresentada à UEM pelo primeiro autor.

2 Zoot., Prof., Departamento de Medicina Veterinária, Universidade Paranaense (UNIPAR), Umuarama, PR.

${ }^{3}$ Zoot., Dr., Prof. Assoc., Departamento de Zootecnia, Universidade Estadual de Maringá (UEM), CEP: 87020-900, Maringá, PR

E.mail: cefurtado@uem.br

${ }^{4}$ Estudante de Graduação em Zootecnia, UEM, Bolsista PIBIC-CNPq

${ }^{5}$ Estudante de Graduação em Zootecnia, UEM.
} 


\section{Introdução}

A alimentação representa, na criação de eqüinos, de 70 a $80 \%$ dos custos, constituindo um dos principais fatores para o sucesso da criação. O arraçoamento dos eqüinos deve ser feito com base na fisiologia digestiva para se obter melhor eficiência alimentar e, desse modo, evitar transtornos gastrointestinais (Wolter, 1977).

O conhecimento da composição química e dos valores de digestibilidade dos alimentos permitem formulações de rações que serão mais ajustadas às exigências em nutrientes e energia dos animais, maximizando, assim, o desempenho dos animais e reduzindo os custos.

Existe uma série de fatores que afetam a digestão nos eqüinos - individualidade, composição química dos alimentos, quantidade consumida de alimentos, velocidade de trabalho, grau de moagem dos alimentos, água contida, tempo de trânsito pelo trato digestivo, quantidade de fibra presente na ração e procedimentos analíticos utilizados (Hintz, 1969).

Via de regra, os fenos de gramíneas ou de leguminosas constituem a principal fonte de fibra na formulação de rações destinadas aos eqüinos. Os fenos de leguminosas, normalmente, possuem valores nutricionais mais elevados comparativamente aos de gramíneas (Lewis, 1995). Entretanto, os altos custos dos mesmos e a dificuldade de produção em diversas regiões do país dificultam sua utilização. Os fenos de gramíneas, por outro lado, são produzidos mais facilmente e apresentam custos menores, porém com qualidades nutricionais inferiores.

O interesse pela casca de soja deve-se às suas possíveis vantagens em relação ao feno de gramíneas. Em razão de ser um subproduto industrial largamente produzido no Brasil, pode ser obtido praticamente durante todo o ano, não estando sujeito a grandes alterações de preço sazonais. Segundo Kunkle et al. (1999), a casca de soja possui alto teor de fibra, sendo altamente digestível pelos ruminantes. Por possuir baixo teor de amido, proporciona baixa taxa de fermentação e reduz os problemas de acidose. Apresenta, em sua composição, teor de PB ao redor de $11 \%$, comparável aos fenos de gramíneas de elevada qualidade e ainda apresenta alta disponibilidade energética. Assim, a casca de soja surge como promissor alimento a ser utilizado na alimentação dos eqüinos.

Atualmente, os subprodutos da agroindústria são grande fonte de interesse para pesquisadores e pro- dutores que buscam a cada dia a maximização do desempenho animal associado a baixo custo. Nesse contexto, a casca de soja surge como promissora fonte alimentar alternativa. Devido à sua disponibilidade energética, a casca de soja vem sendo utilizada na substituição total e parcial do milho e de fontes protéicas na alimentação de ruminantes (Mansfield \& Stern, 1994; Gomes, 1998; Ezequiel et al.,1999; Silva, 1999; Thiago et al., 2000; Ezequiel et al., 2000). Por outro lado, experimentos com ruminantes e coelhos avaliaram a casca de soja como substituto do feno de alfafa e de gramínea com bons resultados (Ezequiel et al., 1999; Arruda et al., 2000).

Na literatura consultada, não foram encontrados experimentos avaliando eqüinos alimentados com casca de soja, como fonte de fibra nas rações.

O objetivo do presente trabalho foi, por intermédio de ensaios de digestibilidade aparente e de desenvolvimento, avaliar as substituições parciais e totais do feno de Tifton 85 pela casca de soja na dieta, visando obter uma fonte de fibra alternativa para eqüinos.

\section{Material e Métodos}

O experimento de digestibilidade aparente foi conduzido no setor de Eqüideocultura da Fazenda Experimental de Iguatemi, da Universidade Estadual de Maringá, utilizando-se quatro eqüinos machos, com idade média de 11 meses e peso vivo de $350 \pm 26 \mathrm{~kg}$, em um delineamento experimental em quadrado latino (4 x 4), descrito por Cochran \& Cox (1967).

A quantidade de alimento fornecida aos animais foi estabelecida segundo as recomendações do NRC (1989), visando atender às exigências nutricionais. A ingestão diária de matéria seca, expressa em kg/dia, foi de 2,0\% do peso vivo durante as fases de adaptação e reduzida para $85 \%$ do total na fase de coleta total de fezes. As dietas foram fornecidas em quatro refeições diárias $(8,13,17$ e $22 \mathrm{~h})$ e as sobras, retiradas e pesadas 15 minutos antes de cada refeição. Amostras do alimento foram coletadas no início e final da fase de adaptação, em todos os tratamentos. Os animais foram vermifugados 90, 60 e 30 dias antes ao início do experimento, com vermífugo de amplo espectro à base de Ivermectina (Eqvalan - Merial).

O período experimental teve duração de 40 dias, sendo dividido em quatro períodos de 10 dias subseqüentes, sendo que os cinco primeiros corresponderam à fase de adaptação dos animais às instalações, alimentação e condições de manejo e os cinco últimos,

\section{R. Bras. Zootec., v.33, n.3, p.564-574, 2004}


ao período de coleta total de fezes. Os animais permaneceram confinados individualmente em uma área de $12 \mathrm{~m}^{2}$ com piso de cimento, sem cama e provida de comedouro para ração, bebedouro do tipo "balde” e comedouro para sal mineral fornecido ad libitum.

Os tratamentos constituíram-se de uma dieta referência e três dietas teste, em que a casca de soja substituiu em 33,3, 66,6 e 100\% o feno de Tifton 85 da dieta referência, totalizando quatro tratamentos. A composição química e percentual dos ingredientes da dieta referência e das dietas teste são mostradas nas Tabelas 1 e 2 .

As fezes foram coletadas diuturnamente e pesadas todos os dias, às $8 \mathrm{~h}$, homogeneizadas e retiradas alíquotas de $10 \%$ do total diário. Foram acondicionadas em sacos plásticos, devidamente identificados e armazenados em freezer a $-10^{\circ} \mathrm{C}$.

Ao final da fase experimental, as amostras foram descongeladas à temperatura ambiente, homogeneizadas por tratamento, para obtenção de uma amostra composta para cada animal, das quais foram retiradas alíquotas de $10 \%$, pesadas e présecas em estufa de ventilação forçada a $55^{\circ} \mathrm{C}$, por 72 horas. Após secagem e equilíbrio com a umidade do meio ambiente, foram novamente pesadas, moídas em peneira de $1 \mathrm{~mm}$, devidamente acondicionadas para as análises realizadas no Laboratório de Nutrição Animal, do Departamento de Zootecnia da Uni- versidade Estadual de Maringá, segundo metodologia proposta por Silva (1990).

Os cálculos para determinação dos coeficientes da digestibilidade aparente da matéria seca (CDaMS), proteína bruta (CDaPB), fibra bruta (CDaFB), fibra em detergente ácido (CDaFDA) e fibra em detergente neutro (CDaFDN) das dietas experimentais foram feitos segundo Church (1988).

O modelo estatístico utilizado para a análise do coeficiente de digestibilidade dos nutrientes foi:

$$
\mathrm{Y}_{\mathrm{ij}}=\mu+\mathrm{b}_{1}(\mathrm{Ti}-\mathrm{Tm})+\mathrm{b}_{2}(\mathrm{Ti}-\mathrm{Tm})^{2}+\mathrm{e}_{\mathrm{ij}} \text {, }
$$

em que $Y_{i j}$ é a observação do animal j que recebeu o tratamento $\mathrm{i} ; \mu$, a constante comum a todas as observações; Ti, o efeito do tratamento i, sendo i = 1, 2, 3 e 4; $\mathrm{b}_{1}$, coeficiente linear de regressão de $\mathrm{Y}$, em função do tratamento experimental $(\mathrm{Ti}) ; b_{2}$, coeficiente quadrático de regressão de $\mathrm{Y}$, em função do tratamento experimental (Ti); Tm, tratamento experimental médio; $\mathrm{e}_{\mathrm{ij}}$, erro aleatório associado a cada observação $\mathrm{Y}_{\mathrm{ij}}$.

A análise das variáveis em estudo, relativas à digestibilidade dos nutrientes, foi efetuada utilizando-se a técnica da análise da variância para delineamento em quadrado latino (quatro períodos x quatro animais), com desdobramento dos graus de liberdade de tratamentos. As análises estatísticas foram realizadas utilizando-se o programa SAEG (1997) e para as

Tabela 1 - Composição química dos ingredientes das rações ${ }^{1}$, base na matéria seca

Table 1 - Chemical composition of the ingredients of the diets ${ }^{1}$, dry matter basis

\begin{tabular}{|c|c|c|c|c|c|c|}
\hline $\begin{array}{l}\text { Ingredientes (\%) } \\
\text { Ingredients (\%) }\end{array}$ & $\begin{array}{c}\text { Matéria } \\
\text { seca }^{1}(\%) \\
\text { Dry } \\
\text { matter (\%) }\end{array}$ & $\begin{array}{c}\text { Proteína } \\
\text { bruta (\%) } \\
\text { Crude } \\
\text { protein (\%) }\end{array}$ & $\begin{array}{c}\text { Fibra } \\
\text { bruta (\%) } \\
\text { Crude } \\
\text { fiber (\%) }\end{array}$ & $\begin{array}{l}\mathrm{FDN}^{2}(\%) \\
\operatorname{NDF}^{2}(\%)\end{array}$ & $\begin{array}{l}\mathrm{FDA}^{3}(\%) \\
A D F^{3}(\%)\end{array}$ & $\begin{array}{c}\text { Matéria } \\
\text { mineral (\%) } \\
\text { Mineral } \\
\text { matter (\%) }\end{array}$ \\
\hline $\begin{array}{l}\text { Casca de soja } \\
\text { Soybean hulls }\end{array}$ & 95,57 & 10,58 & 39,68 & 63,96 & 51,61 & 6,01 \\
\hline $\begin{array}{l}\text { Farelo de trigo } \\
\text { Wheat bran }\end{array}$ & 96,15 & 17,01 & 5,41 & 25,01 & 7,79 & 3,39 \\
\hline $\begin{array}{l}\text { Farelo de soja } \\
\text { Soybean meal }\end{array}$ & 97,36 & 44,92 & 6,11 & 13,59 & 13,85 & 3,39 \\
\hline $\begin{array}{l}\text { Milho grão } \\
\text { Corn grain }\end{array}$ & 95,62 & 9,49 & 2,26 & 16,21 & 4,69 & 6,46 \\
\hline $\begin{array}{l}\text { Feno de Tifton } 85 \\
\text { Tifton } 85 \text { hay }\end{array}$ & 96,76 & 6,52 & 39,61 & 81,75 & 49,45 & 6,53 \\
\hline
\end{tabular}

${ }_{1}^{1}$ Análises realizadas no Laboratório de Nutrição do Departamento de Zootecnia da Universidade Estadual de Maringá.

2 FDN - Fibra em detergente neutro.

${ }^{3}$ FDA - Fibra em detergente ácido.

${ }^{1}$ Analyses were performed at the Nutrition Laboratory of Zootecnia Department of Maringá State University.

2 NDF - Neutral detergent fiber.

${ }^{3}$ ADF - Acid detergent fiber.

\section{R. Bras. Zootec., v.33, n.3, p.564-574, 2004}


Tabela 2 - Composição percentual e química das dietas experimentais ${ }^{1}$ Table 2 - Chemical and percent composition of the experimental diets

\begin{tabular}{|c|c|c|c|c|}
\hline $\begin{array}{l}\text { Ingredientes } \\
\text { Ingredients }\end{array}$ & 0 & 33,3 & 66,6 & 100,0 \\
\hline $\begin{array}{l}\text { Casca de soja } \\
\text { Soybean hulls }\end{array}$ & 0,00 & 13,33 & 26,67 & 40,0 \\
\hline $\begin{array}{l}\text { Farelo de trigo } \\
\text { Wheat bran }\end{array}$ & 8,00 & 9,42 & 2,15 & 2,00 \\
\hline $\begin{array}{l}\text { Farelo de soja } \\
\text { Soybean meal }\end{array}$ & 12,22 & 10,15 & 10,47 & 10,00 \\
\hline $\begin{array}{l}\text { Milho } \\
\text { Corn grain }\end{array}$ & 35,30 & 36,00 & 42,12 & 42,40 \\
\hline $\begin{array}{l}\text { Feno de Tifton } 85 \\
\text { Tifton hay }\end{array}$ & 40,00 & 26,67 & 13,33 & 0,00 \\
\hline $\begin{array}{l}\text { Fosfato bicálcico } \\
\text { Dicalcium phosphate }\end{array}$ & 0,95 & 0,89 & 1,10 & 1,60 \\
\hline $\begin{array}{l}\text { Calcário } \\
\text { Limestone }\end{array}$ & 0,76 & 0,75 & 1,38 & 1,00 \\
\hline $\begin{array}{l}\text { Sal comum } \\
\text { Salt }\end{array}$ & 0,78 & 0,79 & 0,80 & 1,00 \\
\hline $\begin{array}{l}\text { Premix }^{2} \\
\text { Premix }^{2}\end{array}$ & 2,00 & 2,00 & 2,00 & 2,00 \\
\hline $\begin{array}{l}\text { Total } \\
\text { Composição analisada }{ }^{3} \\
\text { Analyzed composition }{ }^{3}\end{array}$ & 100,00 & 100,00 & 100,00 & 100,00 \\
\hline $\begin{array}{l}\text { Matéria seca (\%) } \\
\text { Dry matter (\%) }\end{array}$ & 98,38 & 95,97 & 96,24 & 96,54 \\
\hline $\begin{array}{l}\text { Proteína bruta (\%) } \\
\text { Crude protein (\%) }\end{array}$ & 13,17 & 13,69 & 13,75 & 14,00 \\
\hline $\begin{array}{l}\text { Fibra bruta }(\%) \\
\text { Crude fiber (\%) }\end{array}$ & 20,05 & 21,35 & 18,99 & 16,87 \\
\hline $\begin{array}{l}\text { FDN }(\%) \\
N D F(\%)\end{array}$ & 48,74 & 47,63 & 40,56 & 33,83 \\
\hline $\begin{array}{l}\text { FDA }(\%) \\
A D F(\%)\end{array}$ & 26,65 & 26,33 & 24,74 & 22,75 \\
\hline $\begin{array}{l}\text { Cálcio (\%) } \\
\text { Calcium (\%) }\end{array}$ & 0,72 & 0,72 & 0,80 & 0,82 \\
\hline $\begin{array}{l}\text { Fósforo total (\%) } \\
\text { Total phosphorus (\%) }\end{array}$ & 0,45 & 0,45 & 0,45 & 0,54 \\
\hline $\begin{array}{l}\text { Extrato etéreo (\%) } \\
\text { Ether extract (\%) }\end{array}$ & 2,23 & 2,23 & 2,23 & 2,41 \\
\hline $\begin{array}{l}\text { Energia digestível }(\mathrm{kcal} / \mathrm{kg})^{4} \\
\text { Digestible energy }(\mathrm{kcal} / \mathrm{kg})^{4}\end{array}$ & 2.471 & 2.469 & 2.501 & 2.496 \\
\hline
\end{tabular}

${ }^{1}$ Formulada de acordo com as exigências do NRC (1989) para potros em crescimento.

${ }^{2}$ Composição do premix mineral e vitamínico: Cálcio $185 \mathrm{~g}$; Fósforo $180 \mathrm{~g}$; Magnésio $25 \mathrm{~g}$; Zinco 5000 mg; Cobre 1300 mg; Cobalto 350 mg; Manganês 2500 mg; Ferro 3000 mg; Iodo 300 mg; Selênio 20 mg; Flúor 1800 mg; e Vitamina A 50000 Ul.

${ }^{3}$ Análises realizadas no Laboratório de Nutrição do Departamento de Zootecnia da Universidade Estadual de Maringá.

${ }^{4}$ Valor calculado.

${ }^{1}$ Formulated in agreement with NRC (1989), for growing horses.

${ }^{2}$ Mineral vitamin premix contained: Calcium 185 g; Phosphorus 180 g; Magnesium 25 g; Zinc 500 mg: Copper $1300 \mathrm{mg}$; Cobalt $350 \mathrm{mg}$; Manganese 2500 mg; Iron 3000 mg;lodine 300 mg; Selenium 20 mg; Fluoride $1800 \mathrm{mg}$ and Vitamin A $50000 \mathrm{UI}$.

${ }^{3}$ Analyses were performed at the Nutrition Laboratory of Animal Science Department of Maringá State University.

${ }^{4}$ Calculated value. 
conclusões foi considerado o nível de significância de $5 \%$.

O experimento de desenvolvimento dos potros foi conduzido no Haras Três Fronteiras, no município de Paranavaí, Estado do Paraná. Foram utilizados 16 eqüinos machos, da raça Mangalarga, com idade de 15 meses e peso vivo médio de $255,19 \pm 18,85 \mathrm{~kg}$.

O delineamento experimental utilizado foi inteiramente casualizado, com quatro tratamentos, quatro repetições e um animal por unidade experimental. Os tratamentos constituíram-se de uma dieta testemunha e outras três dietas com níveis crescentes de substituição, 33,3; 66,6 e 100\% do feno de Tifton 85 pela casca de soja, resultando na inclusão de 13,3, 26,7 e $40 \%$ de casca de soja, respectivamente. As composições química e percentual dos ingredientes e das dietas encontram-se nas Tabelas 1 e 2.

A quantidade oferecida de alimento aos animais foi estabelecida segundo as recomendações do NRC (1989) e Ott (1995), visando atender às exigências nutricionais para a categoria. As dietas foram fornecidas em duas refeições diárias, às 8h30 e 15h30. O fornecimento da dieta foi realizado na proporção de 2,5\% do PV, expresso em kg de matéria seca. Os animais permaneceram confinados, durante todo o período experimental, em boxes individuais com dimensão de $16 \mathrm{~m}^{2}$. O consumo individual da matéria seca foi corrigido a cada 15 dias, em função do peso vivo dos animais e amostras dos alimentos foram coletadas no início e no final de cada período de 15 dias, para posteriores análises, segundo Silva (1990).

O experimento consistiu de um período de adaptação, com duração de 15 dias, visando adaptar os animais ao manejo, instalações e às rações experimentais. Em seguida, o período experimental teve duração de 75 dias, constituído por cinco períodos consecutivos de 15 dias. Os animais foram avaliados por meio do ganho diário de peso vivo (GDPV), aumento da altura na cernelha (AC), aumento do perímetro torácico (PT) e aumento do perímetro de canela (PC).

No início do período experimental e, subseqüentemente, a cada 15 dias, os animais permaneceram em jejum por 12 horas, quando, então, foram pesados e mensurados. Todas as pesagens e mensurações foram efetuadas pela mesma pessoa e durante o período matutino. A altura na cernelha foi obtida por intermédio de um hipômetro, aplicado sobre o ponto mais alto desta região; o perímetro de canela foi tomado com fita métrica, passando pelo contorno no centro da região; e o perímetro torácico, com fita métrica, colocada logo atrás da cernelha, no nível do nono par de costelas, passando atrás das espáduas e pelo cilhadouro do animal, representando, assim, o contorno da caixa torácica (Lacerda, 1973).

O modelo estatístico utilizado para a análise das características de desenvolvimento foi:

$$
\mathrm{Y}_{\mathrm{ij}}=\mu+\mathrm{b}_{1}(\mathrm{Ti}-\mathrm{Tm})+\mathrm{b}_{2}(\mathrm{Ti}-\mathrm{Tm})^{2}+\mathrm{e}_{\mathrm{ij}}
$$

em que $Y_{i j}$ é a observação do animal j que recebeu o tratamento $\mathrm{i} ; \mu$, a constante comum a todas as observações; Ti, o efeito do tratamento i, sendo i = 1, 2, 3 e 4; $\mathrm{b}_{1}$, coeficiente linear de regressão de $\mathrm{Y}$, em função do tratamento experimental (Ti); $b_{2}$, coeficiente quadrático de regressão de $\mathrm{Y}$, em função do tratamento experimental (Ti); Tm, o tratamento experimental médio; $\mathrm{e}_{\mathrm{ij}}$, o erro aleatório associado a cada observação $\mathrm{Y}_{\mathrm{ij}}$.

Os resultados foram submetidos à análise de variância. As análises estatísticas foram realizadas utilizando-se o programa SAEG (1997) e para as conclusões foi considerado ao nível de significância de $5 \%$.

\section{Resultados e Discussão}

Considerando o experimento de digestibilidade aparente, a inclusão da casca de soja em substituição ao feno de Tifton 85 nas dietas experimentais aumentou de forma linear $(p<0,05)$ os coeficientes de digestibilidade da matéria seca (MS), fibra bruta (FB), fibra em detergente neutro (FDN) e fibra em detergente ácido (FDA) (Tabela 3). Os valores crescentes dos coeficientes de digestibilidade da MS, FB, FDN e FDA obtidos no presente trabalho, com o aumento dos níveis de inclusão da casca de soja, podem ser explicados pelo alto teor de pectina contido neste alimento, constituindo a pectina um carboidrato de parede celular de alta digestibilidade, quando comparado à parede celular de fenos de gramíneas. Nesse sentido, Van Soest (1985) relata que este subproduto, apesar de rico em parede celular, apresenta pouca lignina, teor considerável de pectina e proteína ligada à mesma, indicando que o enriquecimento em nutrientes da digesta que alcança o intestino grosso poderá melhorar o aproveitamento dos carboidratos estruturais.

Por outro lado, não foi observada diferença $(p>0,05)$ sobre o coeficiente de digestibilidade da proteína bruta, independentemente da dieta avaliada. 
Pode-se ressaltar, entretanto, tendência de aumento nos $\mathrm{CDaPB}$, à medida que se elevaram os níveis de inclusão da casca de soja, em substituição ao feno de Tifton 85 nas dietas.

Os coeficientes de digestibilidade aparente da matéria seca do presente trabalho apresentaram valores $(\mathrm{p}<0,05)$ que variaram de 62,48 a $82,77 \%$ para os níveis crescentes de inclusão de casca de soja. Estes valores podem ser considerados satisfatórios para estudos de digestibilidade em dietas para eqüinos. Experimentos com eqüinos machos, de diferentes idades e utilizando rações completas, com algumas variações nos ingredientes utilizados, relataram valores de digestibilidade aparente da matéria seca variando de 58,2 a 86,5\% (Pereira et al., 1989; Manzano \& Manzano, 1990; Araújo, 1992; Whitaker \& Carvalho, 1997; Almeida et al., 1998; Gonçalves et al., 1998; Oliveira \& Furtado, 2001; Santos et al., 2002).

Os mesmos autores acima citados relataram coeficientes de digestibilidade aparente da proteína bruta variando de 60,83 a 85,9\%. Cymbaluk (1990), em pesquisa com potros e avaliando dietas à base de farelo de canola, relatou valor médio de 73,7\% para o coeficiente de digestibilidade aparente da proteína bruta. Farley et al. (1995) e Gibbs et al. (1996), em experimentos com eqüinos recebendo dietas com elevados níveis de concentrado, de 60 e $70 \%$, relataram coeficientes de digestibilidade aparente da proteína bruta de 80 e $85 \%$, respectivamente. Os coeficientes de digestibilidade aparente da proteína bruta para todas as dietas avaliadas também mostraram-se satisfatórios, com o valor médio de 72,68\%, superior aos valores comumente obtidos em pesquisas conduzidas com eqüinos submetidos à dietas com rações completas. Almeida et al. (1999) relataram que experimentos publicados com eqüinos recebendo dietas à base de gramíneas e concentrados, com valores médios de $86,9 \%$ de matéria seca e $12,1 \%$ de proteína bruta na sua composição química, apresentaram valores médios de CDaMS e CDaPB de 61,34 e $69,88 \%$, respectivamente. Os autores, entretanto, demonstraram que, na literatura consultada, os coeficientes de digestibilidade podem variar de 27,8 a $88,2 \%$ e de 28,0 a $90,89 \%$, respectivamente, para os CDaMS e CDaPB.

Os coeficientes de digestibilidade aparente da fibra bruta, fibra em detergente ácido e fibra em detergente neutro determinados no presente trabalho, para os tratamentos utilizados, variaram de 66,08

Tabela 3 - Coeficientes da digestibilidade aparente da matéria seca (CDaMS), fibra bruta (CDaFB), fibra em detergente ácido (CDaFDA), fibra em detergente neutro (CDaFDN) e proteina bruta (CDaPB) das rações com diferentes níveis de casca de soja (CS) ${ }^{1}$

Table 3 - Coefficients of apparent digestibility of dry matter (aDCDM), crude fiber (aDCCF), acid detergent fiber (aDCADF), neutral detergent fiber( $a D C N D F)$ and crude protein $(a D C C P)$ in diets with different levels of soybean hulls (SH)

\begin{tabular}{|c|c|c|c|c|c|c|}
\hline $\begin{array}{l}\text { Variable } \\
\text { Variable }\end{array}$ & $\begin{array}{l}0-\mathrm{CS} \\
0-\mathrm{SH}\end{array}$ & $\begin{array}{l}\text { 33,3-CS } \\
33.3-S H\end{array}$ & $\begin{array}{l}66,6-\mathrm{CS} \\
66.6-\mathrm{SH} \\
\end{array}$ & $\begin{array}{l}100,0-\mathrm{CS} \\
100.0-\mathrm{SH}\end{array}$ & $\begin{array}{c}\text { Efeitos principais } \\
\text { Principal effects }\end{array}$ & $\mathrm{CV}^{4}$ \\
\hline $\begin{array}{l}\mathrm{CDaMS}^{2} \\
a D C D M^{2}\end{array}$ & 62,48 & 66,35 & 79,49 & 82,77 & $\hat{\mathrm{Y}}=61,68+0,22 \mathrm{X}\left(\mathrm{r}^{2}=0,69\right)$ & 7,62 \\
\hline $\begin{array}{l}\mathrm{CdaFB}^{2} \\
A D C C F^{2}\end{array}$ & 66,08 & 65,16 & 75,41 & 74,09 & $\hat{\mathrm{Y}}=65,05+0,10 \mathrm{X}\left(\mathrm{r}^{2}=0,68\right)$ & 10,64 \\
\hline $\begin{array}{l}\mathrm{CDaFDA}^{2} \\
A D C A D F^{2}\end{array}$ & 61,12 & 57,15 & 73,34 & 72,27 & $\hat{\mathrm{Y}}=58,53+0,15 \mathrm{X}\left(\mathrm{r}^{2}=0,80\right)$ & 11,11 \\
\hline $\begin{array}{l}\mathrm{CDaFDN}^{2} \\
A D C N D F^{2}\end{array}$ & 62,59 & 62,62 & 75,17 & 74,05 & $\hat{\mathrm{Y}}=61,57+0,14 \mathrm{X}\left(\mathrm{r}^{2}=0,78\right)$ & 9,12 \\
\hline $\begin{array}{l}\mathrm{CDaPB}^{3} \\
a D C C P^{3}\end{array}$ & 69,67 & 71,95 & 74,08 & 75,03 & $\hat{\mathrm{Y}}=72,68$ & 10,37 \\
\hline
\end{tabular}

${ }^{1}$ Dados obtidos no Laboratório de Nutrição do Departamento de Zootecnia da Universidade Estadual de Maringá.

2 Médias diferem significativamente $(P<0,05)$.

${ }^{3}$ Médias não diferem significativamente $(P>0,05)$.

${ }^{4} \mathrm{CV}=$ Coeficiente de variação.

1 Analyses were performed at the Nutrition Laboratory of Animal Science Department of Maringá State University.

2 Effects were noticed on the diets $(P<.05)$.

${ }^{3}$ No effects were noticed on the diets $(P>.05)$.

${ }^{4} \mathrm{CV}=$ Coefficient of variation. 
a $74,09 \%$, de 66,12 a 72,27 e de 62,59 a $74,05 \%$, respectivamente. Estes foram bem superiores aos valores encontrados em pesquisas com eqüinos submetidos a rações completas, as quais apresentaram valores de coeficiente de digestibilidade aparente para FDN variando de 44,2 a $58,8 \%$ e para FDA, de 27,5 a 42,3\% (Cymbaluk, 1990; Araújo, 1992; Whitaker \& Carvalho, 1997; Rezende et al., 1998; Oliveira \& Furtado, 2001). Utilizando éguas em experimentos com a técnica do saco de naylon móvel, Araújo et al. (1996) relataram valores de coeficientes de digestibilidade aparente da FDN do milho, farelo de soja e da raspa integral de mandioca de 71,6; 74,7 e $69,0 \%$, respectivamente, os quais foram próximos aos obtidos no presente trabalho em todas as dietas. Santos et al. (2002), utilizando potros com idade ao redor de 11 meses e recebendo ração com silagem de grãos úmidos de milho, determinaram valores de digestibilidade aparente para FB, FDN e FDA de 50,14; 57,5 e 42,3\%, respectivamente. Almeida et al. (1999) relataram que experimentos publicados com eqüinos recebendo dietas à base de gramíneas e concentrado, com valores médios de composição química de $20,2 \%$ de FB, 52,9\% de FDN e 25,11\% de FDA, apresentaram valores médios de coeficiente de digestibilidade de 40,4; 48,3 e 37,9\%, respectivamente. Entretanto, os autores relatam que os valores experimentais podem variar de 17,6 a $65,5 \%, 16,9$ a $71,2 \%$ e 12,8 a $63,9 \%$, respectivamente, para os coeficientes de digestibilidade aparente da FB, FDN e FDA.

As diferenças entre os valores de coeficiente de digestibilidade aparente obtidos no presente trabalho e os encontrados na literatura consultada podem ser explicados por inúmeros fatores que afetam a digestão dos eqüinos (Hintz, 1969).

Os resultados apresentados no presente trabalho estão, de certo modo, em concordância com pesquisas realizadas com bovinos e coelhos. Ezequiel et al. (1999) determinaram os coeficientes de digestibilidade aparente total de rações para bovinos com dois níveis de casca de soja, de 30 e $70 \%$. Segundo esses autores, os níveis de casca de soja afetaram significativamente os coeficientes de digestibilidade aparente total, com o aumento da inclusão do alimento. Para os níveis de substituição de 30 e $70 \%$, os coeficientes de digestibilidade aparente total da MS, PB e FDN foram de 60,5 e $69,1 \%$, 48,1 e $57,8 \%$ e 60,0 e $66,8 \%$, respectivamente.

Os resultados obtidos também são condizentes com Ezequiel et al. (2000), que, estudando os efeitos da substituição parcial do feno de capim-coastcross pela casca de soja sobre a degradabilidade da fibra em detergente neutro em bovinos, observaram que a casca de soja apresentou valores bem mais elevados de degradabilidades, frações insolúveis e degradáveis e menores de fração insolúvel e indegradável. Observaram também que os valores obtidos para a casca de soja foram mais elevados que aqueles obtidos para o feno de capim-coastcross. Também estão condizentes com Arruda et al. (2000), que, avaliando desempenho de coelhos em crescimento alimentados com rações contendo diferentes fontes de fibra e níveis de amido, observaram que as rações contendo casca de soja proporcionaram melhores índices de conversão alimentar quando comparadas com rações contendo feno de alfafa. Estes resultados também corroboram os obtidos por Silva (1999), que, avaliando a degradabilidade ruminal da casca de soja e fontes protéicas e seus efeitos nas digestões ruminal e intestinal de rações de bovinos, concluíram que a casca de soja possui parede celular altamente fermentável.

Considerando o experimento de desenvolvimento, os valores de ganho de peso médio diário (GPMD) de eqüinos alimentados com diferentes níveis de substituição do feno de Tifton pela CS são mostrados na Tabela 4. Os resultados obtidos para GPMD não tiveram efeito $(\mathrm{P}>0,05)$ dos níveis crescentes de casca de soja nas dietas.

O ganho de peso médio diário dos animais que receberam casca de soja foi de $0,635 \mathrm{~kg}$, satisfatório para eqüinos em crescimento e superior às recomendações do NRC (1989). Os valores médios obtidos nesta pesquisa estiveram abaixo dos valores relatados por Hintz et al. (1979) e Thompson (1995), entretanto, estes autores utilizaram potros da raça Puro Sangue Inglês, animais com maior taxa de crescimento quando comparados às raças nacionais.

Na literatura consultada, não foram encontrados experimentos avaliando o desenvolvimento de eqüinos, quando submetidos a dietas com casca de soja. Todavia, os resultados obtidos nesse experimento para ganho de peso foram superiores aos encontrados por Tosi et al. (1979), que em trabalho pioneiro, avaliando o desenvolvimento de potras da raça Brasileiro de Hipismo, alimentadas com silagem de milho mais três quilos de concentrado por dia, obtiveram ganho médio diário de 0,430 kg. Manzano et al. (1979) obtiveram ganhos médios de 0,450 kg, utilizando potras da raça Árabe com 15 meses de idade, arraçoadas com capim-elefante, feno de Rhodes e

\section{R. Bras. Zootec., v.33, n.3, p.564-574, 2004}


60\% de concentrado. Manzano et al. (1987), trabalhando com substituição da espiga de milho desintegrada com palha e sabugo pela mandioca integral seca, obtiveram ganhos médios diários de $0,415 \mathrm{~kg}$, para potras Árabe com 12 meses de idade, e 0,264kg, para os animais com 18 meses de idade. Manzano \& Manzano (1990), utilizando diferentes níveis de guandu como volumoso na dieta de potras em crescimento, obtiveram ganho médio diário de $0,530 \mathrm{~kg}$.

Avaliando a substituição do milho pelo sorgo, em dietas de potros, Whitaker \& Carvalho (1997) verificaram valores de $0,576 \mathrm{~kg}$ para ganho de peso médio diário. Avaliando potros de 12 meses de idade, Oliveira et al. (2001) estudaram a substituição do farelo de soja por farelo de canola e Santos et al. (2002), avaliando a substituição do grão de milho pela silagem de grãos úmidos de milho, obtiveram, respectivamente, ganhos médios diários de 0,691 e 0,720 kg por cabeça dia, valores próximos aos encontrados nesta pesquisa. Dessa forma, observa-se que a média do ganho de peso diário obtido com os animais neste estudo demonstrou que a substituição do feno de Tifton 85 pela casca de soja proporcionou ótimo desempenho quanto ao ganho de peso dos eqüinos. Deve-se ressaltar, entretanto, que os autores citados trabalharam com animais de diferentes raças, idades, períodos variáveis, diferentes alimentos e diversas formulações de dietas.

Segundo Hintz et al. (1979), a avaliação do crescimento através do tamanho corporal, por unidade de tempo, fornece dados que podem ser usados para comparar efeitos de tratamentos ou descrever a taxa de crescimento dos animais que resultam na produção de curvas de crescimento.

Não foram observadas diferenças $(\mathrm{P}>0,05)$ sobre altura na cernelha (AC), perímetro torácico (PT) e perímetro de canela (PC) dos potros alimentados com dietas contendo diferentes níveis de substituição do feno de Tifton 85 por casca de soja. Os valores obtidos para o desenvolvimento estão apresentados na Tabela 5.

Os valores obtidos nesta pesquisa para ganho total médio em AC, de 3,59 cm, foram satisfatórios para os animais na idade avaliada, porém inferiores aos valores obtidos por Hintz et al. (1979), Furtado et al. (1988), Manzano \& Manzano (1990), Thompsom (1995), Whitaker \& Carvalho (1997) e Oliveira et al. (2001), os quais verificaram valores de ganho total em AC, para períodos de 75 dias, variando de 3,83 a $5,58 \mathrm{~cm}$, para animais da mesma idade. Santos et al. (2002) verificaram ganho total médio de AC de 3,53 cm para potros Mangalarga com idade média de 12 meses, no mesmo período, valor muito próximo ao encontrado neste trabalho.

O ganho médio total em PT, de $8,72 \mathrm{~cm}$, obtido neste experimento, mostrou-se semelhante aos relatados por Manzano \& Manzano (1990), Whitaker \& Carvalho (1997) e Oliveira et al. (2001), que obtiveram valores de 6,0; 8,3; e 9,5cm, respectivamente; no entanto, foi inferior aos obtidos por Furtado et al. (1988), Whitaker et al. (1995) e Santos et al. (2002), que relataram valores de 12,$0 ; 15,5$ e $10,95 \mathrm{~cm}$, respectivamente.

Tabela 4 - Ganho de peso médio diário (GPMD/kg/animal) de eqüinos alimentados com diferentes níveis (\%) de substituição do feno de Tifton pela casca de soja (CS)

Table 4 - Average daily gain (ADG/kg/animal) on equine fed diet with different levels (\%) of soybean hulls $(\mathrm{SH})$ replacement

\begin{tabular}{|c|c|c|c|c|c|c|}
\hline $\begin{array}{l}\text { Variável } \\
\text { Variable }\end{array}$ & $\begin{array}{l}0-\mathrm{CS} \\
0-\mathrm{SH}\end{array}$ & $\begin{array}{l}\text { 33,3-CS } \\
\text { 33.3-SH }\end{array}$ & $\begin{array}{l}\text { 66,6-CS } \\
\text { 66.6-SH }\end{array}$ & $\begin{array}{l}100-\mathrm{CS} \\
100-\mathrm{SH}\end{array}$ & $\begin{array}{l}\text { Média } \\
\text { Average }\end{array}$ & $\mathrm{CV}(\%)^{1}$ \\
\hline $\begin{array}{l}\mathrm{PMI}^{2}(\mathrm{~kg}) \\
I A W^{2}(\mathrm{~kg})\end{array}$ & 260 & 261,25 & 247,75 & 251,75 & 255,19 & \\
\hline $\begin{array}{l}\operatorname{PMF}^{3}(\mathrm{~kg}) \\
F A W^{3}(\mathrm{~kg})\end{array}$ & 308,75 & 308,75 & 295 & 298,75 & 302,81 & \\
\hline $\begin{array}{l}\text { GPMD (kg/dia) } \\
\text { ADG (kg/dia) }\end{array}$ & 0,650 & 0,633 & 0,630 & 0,626 & 0,635 & 11,636 \\
\hline
\end{tabular}

${ }^{1} \mathrm{CV}=$ coeficiente de variação.

2 Peso médio inicial.

3 Peso médio final.

${ }^{1} \mathrm{CV}=$ coefficient of variation.

2 Initial average weight

${ }^{3}$ Final average weight.

R. Bras. Zootec., v.33, n.3, p.564-574, 2004 
Tabela 5 - Desenvolvimento de eqüinos alimentados com rações contendo diferentes níveis de casca de soja (CS) em substituição ao feno de Tifton 85

Table 5 - Development of equine fed diet with different levels of soybean hull (SH) replacing Tifton hay 85

\begin{tabular}{|c|c|c|c|c|c|}
\hline Variáveis & 0-CS & 33,3-CS & 66,6-CS & 100-CS & $\mathrm{CV}(\%)^{1}$ \\
\hline Variables & $0-S H$ & 33.3-SH & 66.6-SH & 100-SH & \\
\hline \multicolumn{6}{|c|}{ Altura na cernelha $(\mathrm{cm})$} \\
\hline \multicolumn{6}{|c|}{ Heigh wither $(\mathrm{cm})$} \\
\hline Inicial & 140,38 & 138,75 & 138,75 & 140,75 & 2,432 \\
\hline \multicolumn{6}{|l|}{ Initial } \\
\hline Final & 143,75 & 141,25 & 142,50 & 144,50 & 1,993 \\
\hline \multicolumn{6}{|l|}{ Final } \\
\hline $\begin{array}{l}\text { Ganho total } \\
\text { Total gain }\end{array}$ & 3,37 & 3,50 & 3,75 & 3,75 & 38,68 \\
\hline \multicolumn{6}{|c|}{ Perímetro torácico $(\mathrm{cm})$} \\
\hline \multicolumn{6}{|c|}{ Heart girth $(\mathrm{cm})$} \\
\hline Inicial & 144,50 & 141,88 & 142,50 & 142,50 & 3,177 \\
\hline \multicolumn{6}{|l|}{ Initial } \\
\hline Final & 153,25 & 151,25 & 150,75 & 151,00 & 2,735 \\
\hline \multicolumn{6}{|l|}{ Final } \\
\hline Ganho total & 8,75 & 9,38 & 8,25 & 8,50 & 18,784 \\
\hline \multicolumn{6}{|l|}{ Total gain } \\
\hline \multicolumn{6}{|c|}{ Perímetro de canela $(\mathrm{cm})$} \\
\hline \multicolumn{6}{|c|}{ Cannon bone circunference $(\mathrm{cm})$} \\
\hline Inicial & 16,37 & 16,00 & 15,87 & 16,75 & 4,022 \\
\hline \multicolumn{6}{|l|}{ Initial } \\
\hline Final & 17,37 & 17,13 & 17,13 & 17,75 & 3,456 \\
\hline \multicolumn{6}{|l|}{ Final } \\
\hline Ganho total & 1,00 & 1,13 & 1,25 & 1,00 & 36,738 \\
\hline Total gain & & & & & \\
\hline
\end{tabular}

${ }^{1} \mathrm{CV}=$ Coeficiente de variação.

${ }^{1} \mathrm{CV}=$ Coefficient of variation

Trabalhando com eqüinos em crescimento, com idades em torno de 12 meses, Hintz et al. (1979), Oliveira et al. (2001) e Santos et al. (2002) verificaram valores de ganho total em perímetro de canela, para um período de 75 dias, de 0,92; 0,84 e 1,50 cm respectivamente. Estes valores foram semelhantes ao valor médio para o ganho total em PC obtido nesta pesquisa, de 1,09 cm.

Deve-se ressaltar que todos os autores citados utilizaram eqüinos de sexo e raças diferentes e formulações de dietas diferentes das utilizadas nesta pesquisa.

Durante todo o período experimental, não se verificaram efeitos negativos de ingestão e/ou palatabilidade no uso das rações com casca de soja, como também não foram observados distúrbios gastrointestinais.

\section{Conclusões}

As dietas para eqüinos em crescimento podem ser formuladas com substituição parcial e total do feno de Tifton 85 pela casca de soja, sem afetar adversamente a digestibilidade da proteína bruta, alterando positivamente a digestibilidade da matéria seca, fibra bruta, fibra em detergente neutro e fibra em detergente ácido.

As dietas para eqüinos em crescimento podem ser formuladas com substituição total do feno de Tifton 85 pela casca de soja, com nível de inclusão de $40 \%$ da matéria seca, sem prejuízo sobre o desempenho dos animais. 


\section{Literatura Citada}

ALMEIDA, F.Q.; VALADARES FILHO, S.C.; QUEIROZ, A.C. et al. Digestibilidade aparente e verdadeira pré-cecal e total da proteína em dietas com diferentes níveis protéicos em eqüinos. Revista Brasileira de Zootecnia, v.27, n.3, p.521-529, 1998.

ALMEIDA, M.I.V.; FERREIRA, W.M.; ALMEIDA, F.Q. et al. Composição química e predição do valor nutritivo de dietas para eqüinos. Revista Brasileira de Zootecnia, v.28, n.6, p.1268-1278, 1999.

ARAÚJO, L.D.O. Comparação da digestibilidade aparente em eqüinos submetidos a dieta composta de concentrado e volumosos, fornecidos com diferentes intervalos de tempo. Belo Horizonte:Universidade Federal de Minas Gerais, 1992. 72p. Dissertação (Mestrado em Zootecnia) Universidade Federal de Minas Gerais, 1992.

ARAÚJO, K.V.; LIMA, J.A.F.; TEIXEIRA, J.C. et al. Determinação da digestibilidade aparente dos nutrientes de alguns concentrados e volumosos para eqüinos, pela técnica dos sacos de náilon móvel. Revista Brasileira de Zootecnia, v.25, n.5, p.944-956, 1996.

ARRUDA, A.M.V.; LOPES, D.C.; SILVA, J.F. et al. Desempenho de coelhos em crescimento alimentados com rações contendo diferentes fontes de fibra e níveis de amido. In: REUNIÃO ANUAL DA SOCIEDADE BRASILEIRA DE ZOOTECNIA, 37., 2000, Viçosa, MG. Anais... Viçosa, MG: Sociedade Brasileira de Zootecnia, 2000. p.503.

CHURCH, D.C. The ruminant animal. Digestive physiology and nutrition. Englewood Cliffs: Prentice Hall, 1988. 564p.

COCHRAN, W.G.; COX, G.M. Experimental designs. New York: John Wiley and Sons, 1967. 617p.

CYMBALUK, N.F. Using canola meal in growing draft horse diet. Equine Practice, v.12, n.4, p.16-19, 1990.

EZEQUIEL, J.M.B.; MENDES, A.R.; SILVA, L.D.F. et al. Estimativa da digestibilidade através da FDN indigestível de rações contendo dois níveis de casca soja e diferentes fontes protéicas em novilhos mestiços. In: REUNIÃO ANUAL DA SOCIEDADE BRASILEIRA DE ZOOTECNIA, 36., 1999, Porto Alegre. Anais... Porto Alegre: Sociedade Brasileira de Zootecnia, 1999. p.294.

EZEQUIEL, J.M.B.; GALATI, R.L.; FEITOSA, J.V. Efeito da substituição parcial do feno de capim coast-cross pela casca de soja sobre a degradabilidade da fibra em detergente neutro. In: REUNIÃO ANUAL DA SOCIEDADE BRASILEIRA DE ZOOTECNIA, 37., 2000, Viçosa, MG. Anais... Viçosa, MG: Sociedade Brasileira de Zootecnia, 2000. p.417.

FARLEY, E.B.; POTTER, G.D.; GIBBS, P.G. et al. Digestion of soybean meal protein in the equine small and large intestine at various levels of intake. Journal of Equine Veterinary Science, v.66, n.2, p.400-406, 1995.

FURTADO, C. E.; TOSI, H.; SANTOS, G.F.S. et al. Comparação entre a suplementação com volumosos e a de concentrado na alimentação de eqüinos em crescimento. Pesquisa Agropecuária Brasileira, v.23, n.12, p.1439-1448, 1988.

GIBBS, P.G.; POTTER, G.D.; SCHELLING, G.T. et al. The significance of small vs large intestinal digestion of cereal grain and oilseed protein in the equine. Journal of Equine Veterinary Science, v.16, n.2, p.60-65, 1996.

GONÇALVES, L.C.; REZENDE, A.S.C.; CARVALHO, M.A.G. et al. Digestibilidade aparente em eqüídeos submetidos a três condutas de arraçoamento. I. Matéria seca, proteína bruta e energia bruta. Arquivo Brasileiro de Medicina Veterinária e Zootecnia, v.50, n.4, p.421-427,1998.

GOMES, I.P.O. Substituição do milho pela casca de soja em dietas com diferentes proporções de volumoso: concentrado para bovinos em confinamento. Jaboticabal: Universidade Estadual Paulista,1998. 84p. Tese (Doutorado em Zootecnia) - Universidade Estadual Paulista,1998.

HINTZ, H.F. Comparison of digestion coefficient obtained with cattle, sheep, rabbits and horse. Journal of Animal Science, v.28, n.5, p.1045-1066,1969.

HINTZ, H.F.; HINTZ, R.L.; VLECK, L.D.V. Growth rate of thoroughbreds. Effects of age of dam, year and month of birth, and sex of foal. Journal of Animal Science, v.48, n.3, p.480-487, 1979

KUNKLE, W.E.; STEWART, R.L.; BROWN, W.F. Using byproduct feeds in supplementation programs. University of Florida-Department of Animal Sciences. Disponível em: http://www.animal.ufl.edu/short95/kunkle.pdf (acesso em 7 nov. 1999).

LACERDA, P.C. Estudo biométrico dos eqüinos puro sangue inglês. Anuário do Turf e Criação, v.1, n.1, p.38-46, 1973.

LEWIS, L.D. Feeding and care of the horse. 2.ed. Media: Willians and Wilkins, 1995. 446p.

MASNFIELD, H.R.; STERN, M.D. Effects of soybean hulls and lignosulfonate-treated soybean meal on ruminal fermantation in lactating dairy cows. Jounal of Dairy Science, v.77, n.4, p.1070-1083, 1994.

MANZANO, A.; MANZANO, M.F.F.L. Utilização do guandu (Caianus caian (L) Millsp) na alimentação de eqüinos. Revista Brasileira de Zootecnia, v.19, n.6, p.459-468, 1990.

MANZANO, A.; NOVAES, N.J.; CARVALHO, R.T.L. Substituição do feno de alfafa por feno de Rhodes no desempenho de eqüinos. Pesquisa Agropecuária Brasileira, v.14, n.3, p.229-235, 1979.

MANZANO, A.; NOVAES, N.J.; ESTEVES, S.N. et al. Substituição da espiga de milho desintegrada com palha e sabugo pela mandioca integral seca na alimentação de eqüinos. Revista Brasileira de Zootecnia, v.16, n.3, p.275-283, 1987.

NATIONAL RESEARCH COUNCIL - NRC. Requeriments of domestic animals. Nutrient requeriments of horses. 5.rev.ed. Washington, D.C.: National Academy of Sciences, 1989. 100p.

OLIVEIRA, K.; FURTADO, C.E.; GRAÇA, E.P. Desempenho e parâmetros sangüíneos de equinos em crescimento submetidos a dietas com diferentes níveis de farelo de canola. Revista Brasileira de Zootecnia, v.30, n.1, p.174-180, 2001.

OLIVEIRA, K.; FURTADO C.E. Digestibilidade aparente de dietas com diferentes níveis de farelo de canola para cavalos. Revista Brasileira de Zootecnia, v.30, n.1, p.181-186, 2001.

OTT, E.A. Dietary nutrient allowances for horses. Feedstuffs, v. 64, n.29, p.77-80, 1995.

PEREIRA, J.C.; CARMO, M.B.; MOTTA, V.A.F. et al. Feno de aveia associado ao concentrado em diferentes proporções na alimentação de eqüinos. Revista Brasileira de Zootecnia, v.18, n.5, p.359-366, 1989

REZENDE, A.S.C.; GONÇALVES, L.C.; CARVALHO, M.G.M Digestibilidade aparente em eqüídeos submetidos a três condutas de arraçoamento. II. Frações fibrosas. Arquivo Brasileiro de Medicina Veterinária e Zootecnia, v.50, n.4, p.429-434, 1998.

SANTOS, C.P.; FURTADO, C.E.; JOBIM, C.C. et al. Avaliação da silagem de grãos úmidos de milho na alimentação de eqüinos em crescimento: valor nutricional e desempenho. Revista Brasileira de Zootecnia, v.31, n.3, p.1214-1222, 2002. 
SILVA, D.J. Análise de alimentos (métodos químicos e biológicos).Viçosa, MG: Universidade Federal de Viçosa, 1990. 165p.

SILVA, L.D.F. Degradabilidade ruminal da casca de soja e fontes protéicas e seus efeitos nas digestões ruminal e intestinal de rações de bovinos. Jaboticabal: Universidade Estadual Paulista, 1999.110p. Tese (Doutorado em Zootecnia) - Universidade Estadual Paulista,1999.

THIAGO, L.R.L.S.; SILVA, J.M.; FEIJÓ, G.L.D. et al. Substituição do milho pelo sorgo ou casca de soja em dietas para a engorda de bovinos em confinamento. In: REUNIÃO ANUAL DA SOCIEDADE BRASILEIRA DE ZOOTECNIA, 37., 2000, Viçosa, MG. Anais... Viçosa, MG: Sociedade Brasileira de Zootecnia, 2000. p.484.

THOMPSON, K.N. Skeletal growth rates of wealing and yearling thoroughbred horses. Journal of Animal Science, v.73, n.9, p.2513-2517, 1995.

TOSI, H.; SILVEIRA, A.C.; SALMON, P. et al. Silagem de milho para potras em crescimento. Revista Brasileira de Zootecnia, v.8, n.3, p.365-375, 1979.
UNIVERSIDADE FEDERAL DE VIÇOSA - UFV. SAEG Sistema de análises estatísticas e genéticas. Versão 7.1. Viçosa, MG: 1997. 150p. (Manual do usuário)

Van SOEST, P.J. Definition of fibre in animal feeds. In: HARESIGN, W.; COLE, D.J.A. (Eds.) Recent advances in animal nutrition. Butterworths: London, 1985. p.55-70.

WHITAKER, H.M.A.; CARVALHO, R.L. Substituição do milho pelo sorgo em rações para eqüinos. Revista Brasileira de Zootecnia, v.26, n.1, p.139-143, 1997.

WHITAKER, H.M.A.; SILVA, A.E.; MANZANO, A. et al. Utilização de levedura seca ( Saccharomyces cerevisae) de álcool de cana-de-açúcar em rações para eqüinos. Revista Brasileira de Zootecnia, v.24, n.6, p.1008-1015, 1995.

WOLTER, R. Alimentatión del caballo. Zaragoza: Acribia, 1997. 172p.

Recebido em: 10/12/02

Aceito em: 30/10/03 